\title{
Inflammation on the Cervical Papanicolaou Smear: Evidence for Infection in Asymptomatic Women?
}

\author{
Stavroula Baka, ${ }^{1}$ Ioanna Tsirmpa, ${ }^{1}$ Anthia Chasiakou, ${ }^{1}$ Iliana Tsouma, ${ }^{1}$ Ekaterina Politi, ${ }^{2}$ \\ Vassiliki Gennimata, ${ }^{1}$ and Evangelia Kouskouni ${ }^{1}$ \\ ${ }^{1}$ Biopathology Laboratory, University of Athens, Aretaieio University Hospital, 11528 Athens, Greece \\ ${ }^{2}$ Cytology Laboratory, University of Athens, Aretaieio University Hospital, 11528 Athens, Greece \\ Correspondence should be addressed to Stavroula Baka; sbaka@aretaieio.uoa.gr
}

Received 29 April 2013; Accepted 29 August 2013

Academic Editor: Bryan Larsen

Copyright (C) 2013 Stavroula Baka et al. This is an open access article distributed under the Creative Commons Attribution License, which permits unrestricted use, distribution, and reproduction in any medium, provided the original work is properly cited.

Background. The significance of the possible presence of infection on the Pap smear of asymptomatic women based on cytological criteria is practically unknown. Materials and Methods. A total of 1117 asymptomatic nonpregnant women had Pap smear tests and vaginal as well as cervical cultures completed (622 with and 495 without inflammation on the Pap smear). Results. Out of the 622 women with inflammation on Pap test, 251 (40.4\%) had negative cultures (normal flora present), while 371 (59.6\%) women had positive cultures with different pathogens. In contrast, the group of women without inflammation on Pap test displayed significantly increased percentage of negative cultures $(67.1 \%, P<0.001)$ and decreased percentage of positive cultures $(32.9 \%, P<0.001)$. Bacterial vaginosis was diagnosed more frequently in both groups and significantly more in the group with inflammation on Pap smear compared to the group without inflammation $(P<0.02)$. Conclusions. A report of inflammatory changes on the cervical Pap smear cannot be used to reliably predict the presence of a genital tract infection, especially in asymptomatic women. Nevertheless, the isolation of different pathogens in about $60 \%$ of the women with inflammation on the Pap smear cannot be overlooked and must be regarded with concern.

\section{Introduction}

The infections of the genital tract are common in reproductive-age women and the associated cost is substantial. It has been noted that many women remain asymptomatic in the presence of vaginitis or cervicitis $[1,2]$. The Papanicolaou (Pap) test is a simple, quick, and painless procedure performed on cells from the uterine cervix and used as a screening test for the prevention of the cancer of uterine cervix $[3,4]$. When reporting the results of cervical Pap smears tests usually a remark is made on the possible presence of infection based on cytological criteria [5]. The clinical significance of inflammation on the Pap smear of asymptomatic women is practically unknown since no guidelines exist on appropriate management. Thus clinicians are often faced with the dilemma on whether these women should be counselled to present for vaginal/cervical cultures in order to isolate possible pathogens $[6,7]$. This study assessed the possible association between inflammation on Pap smears and the presence of cervical/vaginal pathogens as determined by cultures.

\section{Materials and Methods}

The population studied consisted of asymptomatic nonpregnant women of reproductive age presenting to the Obstetrics and Gynaecology Outpatient Clinic of Aretaieio University Hospital for a routine Pap smear test between January 2008 and May 2012 and who gave consent to be included in this study. The Ethics Committee of Aretaieio Hospital approved the study, and informed consent forms were obtained from all subjects.

Women were counselled to present to the hospital 10 to 20 days after the first day of their menstrual cycle without using vaginal douche or medication for at least a month. The smears showing inflammatory changes or no inflammation were included in this study, while inadequate smears and smears 
TABLE 1: Culture results in study groups. Figures are numbers (percentages).

\begin{tabular}{lccc}
\hline Culture results & $\begin{array}{c}\text { Inflammation } \\
(n=622)\end{array}$ & $\begin{array}{c}\text { No } \\
\text { inflammation } \\
(n=495)\end{array}$ & $P$ value \\
\hline Negative cultures & $251(40.4)$ & $332(67.1)$ & $<0.001$ \\
Positive cultures & $371(59.6)$ & $163(32.9)$ & $<0.001$ \\
Bacterial vaginosis & 274 & 136 & $<0.02$ \\
Candida spp. & 43 & 12 & NS \\
C. trachomatis & 3 & 0 & NS \\
T. vaginalis & 2 & 0 & NS \\
Aerobic vaginitis & 49 & 15 & NS \\
\hline
\end{tabular}

showing any atypical morphology were excluded. Inflammatory changes as detected on a Pap stained smear included the presence of cells with enlarged nuclei, pyknosis or karyorrhexis, perinuclear halos, and vacuoles. Often increased numbers of polymorphonuclear leukocytes or neutrophils and parabasal cells with generalised eosinophilia of the cells were recorded. Furthermore, the presence of epithelial cells covered with blue-stained coccoid bacteria on the stained cervical smear together with a decreased number or a lack of lactobacilli represented findings suggestive of bacterial vaginosis.

Asymptomatic women with or without inflammatory changes on their Pap smear were recalled for cultures. Genital tract samples (vaginal and cervical) were available for analysis. A wet mount as well as a gram-stained smear was examined under microscope to screen for Trichomonas vaginalis and to obtain valuable information about the microorganisms (yeasts and bacteria) present as well as for the diagnosis of bacterial vaginosis using both Amsel and Nugent criteria [8,9]. The women were tested for the presence of different aerobic bacteria, that is, Candida species, group B streptococcus, Gardnerella vaginalis, and Neisseria gonorrhoeae, and anaerobic bacteria. Thus, clinical specimens collected from patients were inoculated onto appropriate plates for standard aerobic and anaerobic cultures and incubated at $37^{\circ} \mathrm{C}$ for $24 \mathrm{~h}$ and $48 \mathrm{~h}$, respectively. The isolated pathogens were identified using the automated system VITEK 2 (BioMerieux, Marcy l'Etoile, France). Furthermore, the presence of Chlamydia trachomatis as well as Ureaplasma urealyticum and Mycoplasma hominis, in the specimens studied, was determined using the COBAS AMPLICOR Chlamydia trachomatis test (Roche Diagnostics, USA) and Mycoplasma IST2 (BioMerieux, Marcy l'Etoile, France), respectively.

Statistical analysis was performed using chi square test, and values $\leq 0.05$ were considered as significant.

\section{Results}

A total of 1117 women had smear tests and vaginal as well as cervical cultures completed (622 with and 495 without inflammation on the Pap smear). Culture results in the population studied are presented in Table 1 . Women with inflammation on Pap test displayed significantly decreased percentage of negative cultures $(P<0.001)$ and increased percentage of positive cultures $(P<0.001)$. Among the women with genital tract pathogens detected, bacterial vaginosis was diagnosed more frequently in both groups. Interestingly, in the group with inflammation on Pap smear, the women diagnosed with bacterial vaginosis were significantly more compared to the group without inflammation $(P<$ 0.02). The isolation of other pathogens such as Candida species, Chlamydia trachomatis, and $T$. vaginalis and the cases diagnosed as aerobic vaginitis (characterized by the isolation of Streptococcus agalactiae, gram-negative rods, and methicillin-resistant Staphylococcus aureus) did not differ between the two groups.

\section{Discussion}

In our study we carried out vaginal and cervical cultures for a wide range of microorganisms in women with and without inflammation on Pap test in order to determine the predictive value of this finding for the presence of pathogens in asymptomatic women. We established that almost $60 \%$ of the women presenting with inflammatory changes on cervical smear tests had positive cultures for different pathogens. Cervicovaginal microbial flora characterization is necessary, and it would, thus, be opportune for all patients who present with an inflammation on Pap test to undergo a cervicovaginal microbiological examination to detect potential pathogens for correct diagnosis and treatment. Kelly and Black found that $47 \%$ of women with inflammatory changes on cervical smear testing had a microbiologically proven infection [10]. Wilson et al. also reported that inflammation on cytology is often associated with a genital tract infection [11]. Similar findings and comparable to our results were reported in the literature $[2,12,13]$. However, approximately one-third of the women with no inflammatory changes on smear testing had positive cultures. Previous studies demonstrated that women with no inflammatory changes on cervical smears can harbour genital tract pathogens. Bertolino et al. noted that inflammation on Pap smear had a relatively low predictive value for the presence of vaginal pathogens in asymptomatic women [5] while Parsons et al. found a high rate of positive cultures both in women with inflammatory changes and in those without inflammatory changes on smear testing, suggesting that inflammation on Pap test is a poor indicator of cervical infection [6]. On the other hand, Burke and Hickey demonstrated that the prevalence of infection was higher in the inflammatory smear group, thus supporting that women with an inflammatory smear are more likely to harbour genital tract infection than women whose smear shows no evidence of inflammation [7].

Bacterial vaginosis is a condition where an impressive microecologic alteration of vaginal flora takes place characterized by decreased Lactobacillus spp. and overgrowth of Gardnerella vaginalis together with anaerobes and potentially pathogenic bacteria, including Ureaplasma urealyticum, and Mycoplasma hominis. Inflammation on Pap smear has been associated with a $30-50 \%$ incidence of bacterial vaginosis 
$[14,15]$ which is consistent with our findings. Furthermore, others report that most of the smears with inflammatory changes contained clue cells, thus indicating bacterial vaginosis and concluding that Pap smear is well suited in diagnosing cervical infections associated with bacterial vaginosis $[2,7,12]$.

The vaginal flora is a complicated microenvironment which consists of different bacterial species in continuously variable quantities and proportions. Although some pathologic conditions and clinical entities are well defined, the presence of some aerobic microorganisms can be regarded as colonization. In 2002, Donders et al. proposed the term aerobic vaginitis in order to better define a pathologic condition which is correlated with the presence of aerobic bacteria, mainly group B streptococci, Escherichia coli, and Staphylococcus aureus [16]. Interestingly, it has already been reported that Streptococcus agalactiae inhibits the growth of lactobacilli and Gardnerella vaginalis, but not S. aureus [17, 18]. In our study population, the prevalence of $S$. agalactiae and gram-negative rods (mainly E. coli) was lower than a recent report [19], but was similar to that reported by Donders et al. [16] and Lukic et al. [20].

Staphylococcus aureus vaginal colonization has been widely studied since toxic shock syndrome emerged some decades ago. However, vaginal carriage of methicillinresistant $S$. aureus (MRSA) has not been well documented. The prevalence of MRSA was low in our population and similar to previous reports in ambulatory, nonhospitalized, and asymptomatic sample [16, 21].

Forty-three women (11.6\%) with inflammation on Pap smear were positive for Candida infection with the majority of them being diabetic. These findings are consistent with previous results presented in the literature [16], yet not consistent with a recent report where, in a different population, the rate of Candida infection in patients with inflammatory changes was very high, $73.8 \%$ [13]. On the other hand, our findings are high compared to other reports in the literature $[2,6,22]$.

Some studies report on the correlation between evidence of inflammation on smear testing and positive specimens for Chlamydia trachomatis $[5,7,12]$. In our sample, the prevalence of $C$. trachomatis positive testing was $0.8 \%$, which is in accordance with previous reports $[6,13,15]$. Screening for lower genital tract infection, using either an intracervical or a vaginal swab, for Chlamydia infection should be performed even if in some populations the reported prevalence is low since Chlamydia infection, in particular, has long-term fertility consequences through its potential to cause asymptomatic tubal damage.

Trichomonas vaginalis is a parasite that causes symptomatic and asymptomatic infection of the female urogenital system. It has been proven that recovery of $T$. vaginalis was more frequent in women with inflammation on Pap smear than in women without inflammation $[5,12]$. In our study, only two samples were positive for $T$. vaginalis in women with inflammation, which is consistent with others reporting low prevalence $[16,22,23]$ and different from studies that found an increased frequency of this parasite $[2,13]$.

\section{Conclusions}

The results of our study suggest that a report of inflammatory changes on the cervical Pap smear cannot be used to reliably predict the presence of a genital tract infection, especially in asymptomatic women. Further studies with a longitudinal character are needed to look into the possible presence of infection based on cytological criteria. Nevertheless, the isolation of different pathogens in about $60 \%$ of the women with inflammatory changes on the cervical Pap smear, in the absence of Lactobacillus species, cannot be overlooked and must be regarded with concern.

\section{References}

[1] J. M. Klomp, M. E. Boon, M. Van Haaften, and A. P. M. Heintz, "Cytologically diagnosed Gardnerella vaginalis infection and cervical (pre)neoplasia as established in populationbased cervical screening," The American Journal of Obstetrics and Gynecology, vol. 199, no. 5, pp. 480.el-480.e5, 2008.

[2] M. H. Bukhari, M. Majeed, S. Qamar et al., "Clinicopathological study of Papanicolaou (Pap) smears for diagnosing of cervical infections," Diagnostic Cytopathology, vol. 40, no. 1, pp. 35-41, 2012.

[3] G. N. Papanicolaou, "A new procedure for staining vaginal smears," Science, vol. 95, no. 2469, pp. 438-439, 1942.

[4] S. P. Michalas, “The Pap test: George N. Papanicolaou (18831962). A screening test for the prevention of cancer of uterine cervix," European Journal of Obstetrics Gynecology and Reproductive Biology, vol. 90, no. 2, pp. 135-138, 2000.

[5] J. G. Bertolino, J. E. Rangel, R. L. Blake Jr., D. Silverstein, and E. Ingram, "Inflammation on the cervical Papanicolaou smear: the predictive value for infection in asymptomatic women," Family Medicine, vol. 24, no. 6, pp. 447-452, 1992.

[6] W. L. Parsons, M. Godwin, C. Robbins, and R. Butler, "Prevalence of cervical pathogens in women with and without inflammatory changes on smear testing," British Medical Journal, vol. 306, no. 6886, pp. 1173-1174, 1993.

[7] C. Burke and K. Hickey, "Inflammatory smears: is there a correlation between microbiology and cytology findings?" Irish Medical Journal, vol. 97, no. 10, pp. 295-296, 2004.

[8] R. Amsel, P. A. Totten, and C. A. Spiegel, "Nonspecific vaginitis: diagnostic criteria and microbial and epidemiologic associations," The American Journal of Medicine, vol. 74, no. 1, pp. 14-22, 1983.

[9] R. P. Nugent, M. A. Krohn, and S. L. Hillier, "Reliability of diagnosing bacterial vaginosis is improved by a standardized method of gram stain interpretation," Journal of Clinical Microbiology, vol. 29, no. 2, pp. 297-301, 1991.

[10] B. A. Kelly and A. S. Black, "The inflammatory cervical smear: a study in general practice," The British Journal of General Practice, vol. 40, no. 335, pp. 238-240, 1990.

[11] J. D. Wilson, A. J. Robinson, S. A. Kinghorn, and D. A. Hicks, "Implications of inflammatory changes on cervical cytology," British Medical Journal, vol. 300, no. 6725, pp. 638-640, 1990.

[12] G. H. Eltabbakh, G. D. Eltabbakh, F. F. Broekhuizen, and B. T. Griner, "Value of wet mount and cervical cultures at the time of cervical cytology in asymptomatic women," Obstetrics and Gynecology, vol. 85, no. 4, pp. 499-503, 1995. 
[13] R. Al-Awadhi, B. A. Al-Ramadan, S. S. George, P. N. Sharma, and K. Kapila, "Gynecologic infections seen in cervical smears in Kuwait," Acta Cytologica, vol. 54, no. 1, pp. 50-54, 2010.

[14] J. M. Lanouette, K. S. Puder, S. M. Berry, D. R. Bryant, and M. P. Dombrowski, "Is inflammation on papanicolaou smear a risk factor for preterm delivery?" Fetal Diagnosis and Therapy, vol. 12, no. 4, pp. 244-247, 1997.

[15] J. M. Klomp, M. E. Boon, M. Z. Dorman, M. Van Haaften, and A. P. M. Heintz, "Trends in inflammatory status of the vaginal flora as established in the Dutch national screening program for cervical cancer over the last decade," Acta Cytologica, vol. 54, no. 1, pp. 43-49, 2010.

[16] G. G. G. Donders, A. Vereecken, E. Bosmans, A. Dekeersmaecker, G. Salembier, and B. Spitz, "Definition of a type of abnormal vaginal flora that is distinct from bacterial vaginosis: aerobic vaginitis," BJOG, vol. 109, no. 1, pp. 34-43, 2002.

[17] P. Chaisilwattana and G. R. G. Monif, "In vitro ability of the group B streptococci to inhibit gram-positive and gramvariable constituents of the bacterial flora of the female genital tract," Infectious Diseases in Obstetrics and Gynecology, vol. 3, pp. 91-97, 1995.

[18] G. R. G. Monif, "Semiquantitative bacterial observations with group B streptococci," Infectious Diseases in Obstetrics and Gynecology, vol. 7, pp. 227-229, 1999.

[19] H.-S. Shim, S. Noh, A.-R. Park et al., "Detection of sexually transmitted infection and human papillomavirus in negative cytology by multiplex-PCR," BMC Infectious Diseases, vol. 10, pp. 284-291, 2010.

[20] A. Lukic, C. Canzio, A. Patella et al., "Determination of cervicovaginal microorganisms in women with abnormal cervical cytology: the role of Ureaplasma urealyticum," Anticancer Research, vol. 26, no. 6, pp. 4843-4850, 2006.

[21] J. S. Huppert, K. Bennett, L. M. Kollar, L. Pattullo, and J. E. Mortensen, "MRSA: rare in the vagina," Journal of Pediatric and Adolescent Gynecology, vol. 24, no. 5, pp. 315-316, 2011.

[22] S. R. Malkawi, R. M. Abu Hazeem, B. M. Hajjat, and F. K. Hajjiri, "Evaluation of cervical smears at King Hussein Medical Centre, Jordan, over three and a half years," Eastern Mediterranean Health Journal, vol. 10, no. 4-5, pp. 676-679, 2004.

[23] U. Karaman, N. Karadağ, M. Atambay, N. B. Arserim Kaya, and N. U. Daldal, "A comparison of cytological and parasitological methods in the diagnosis of Trichomonas vaginalis," Türkiye Parazitolojii Dergisi, vol. 32, no. 4, pp. 309-312, 2008. 


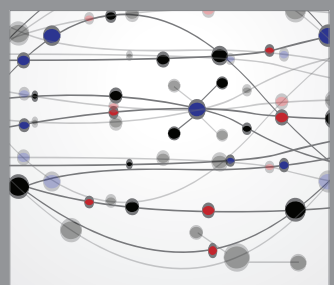

The Scientific World Journal
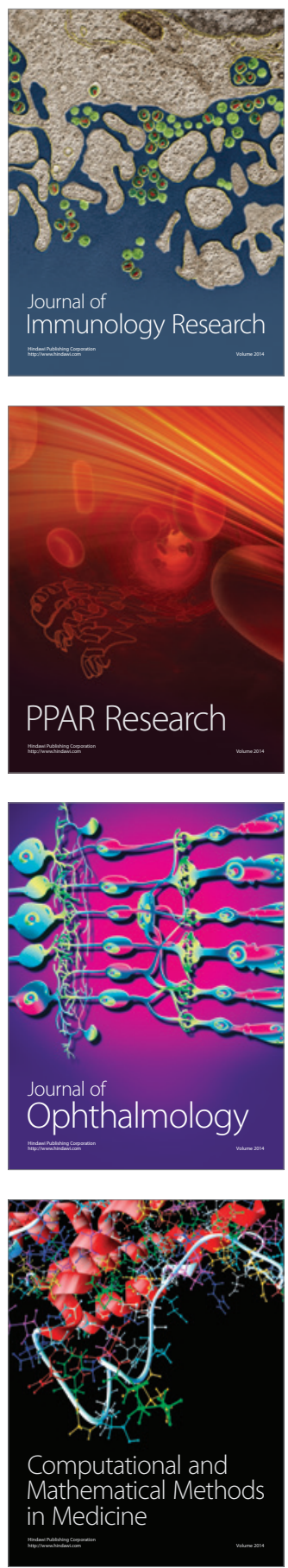

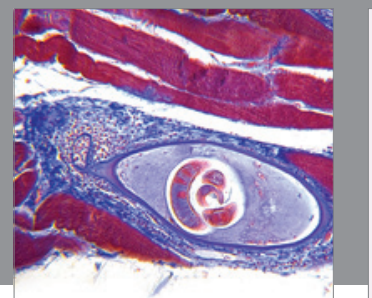

Gastroenterology

Research and Practice
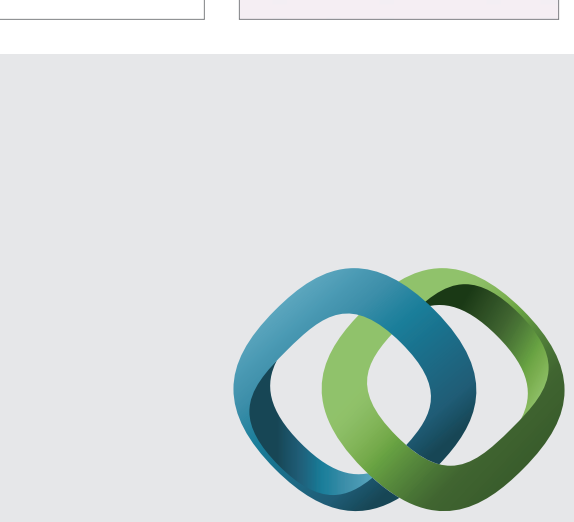

\section{Hindawi}

Submit your manuscripts at

http://www.hindawi.com
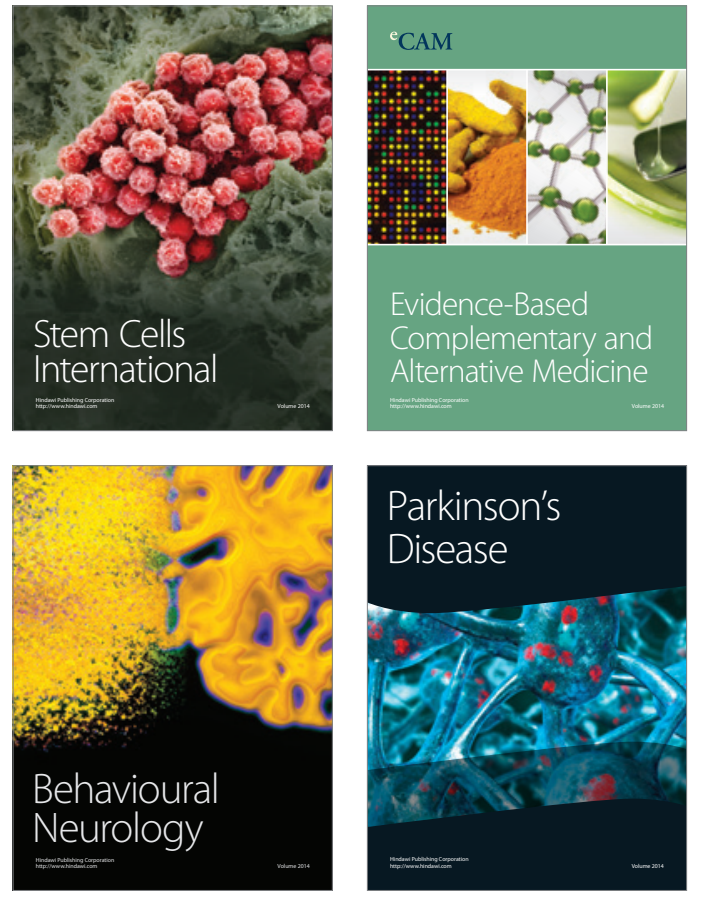
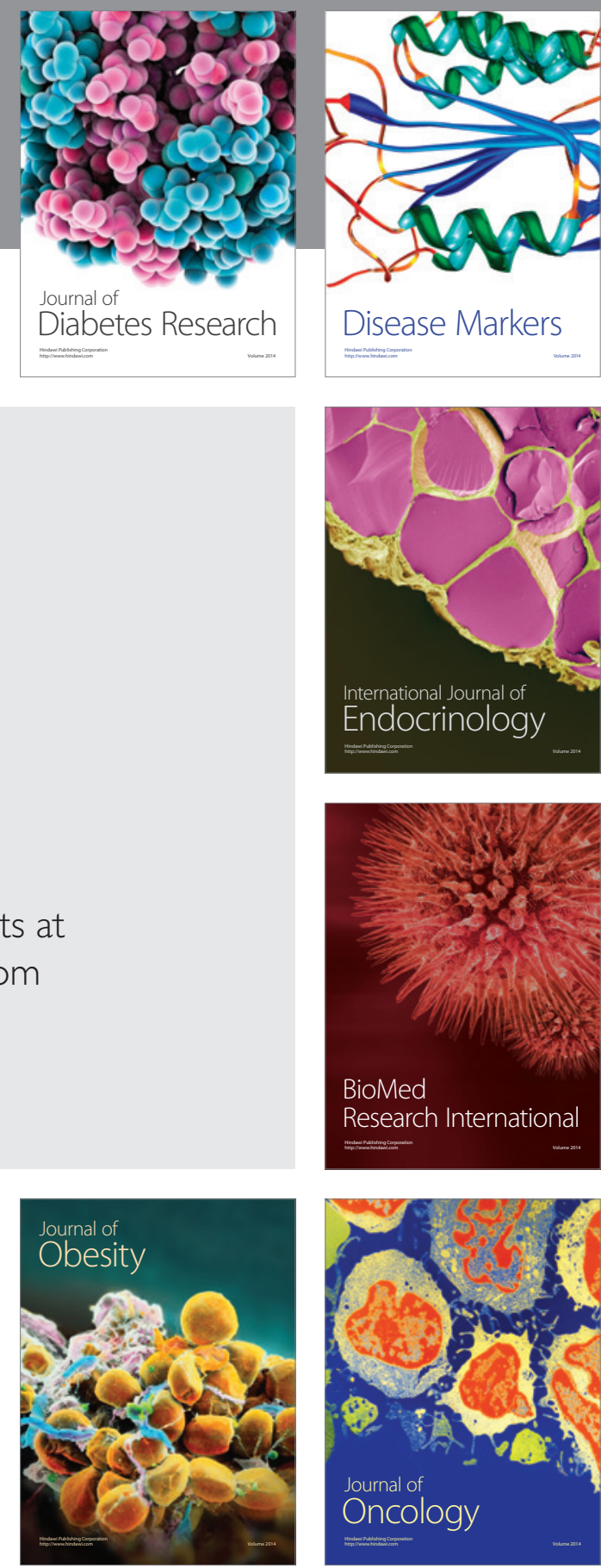

Disease Markers
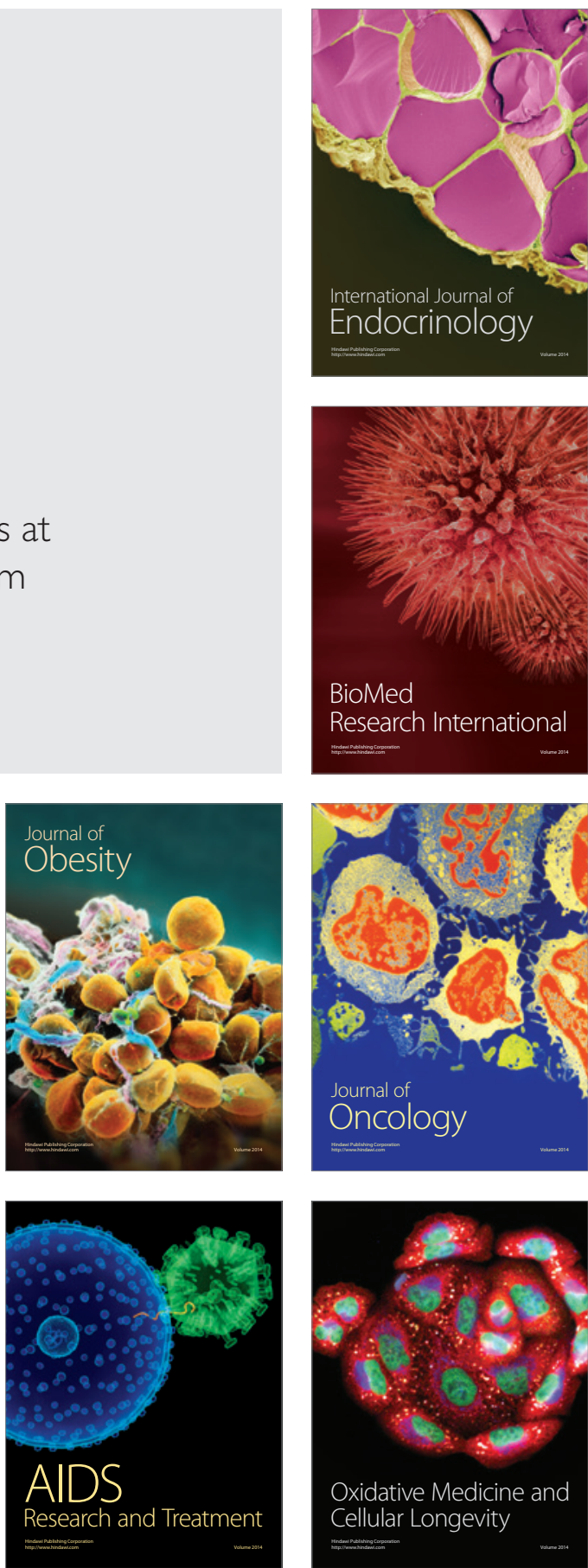